Check for updates

Cite this: Chem. Sci., 2017, 8, 6266

Received 15th May 2017

Accepted 1st July 2017

DOI: $10.1039 / \mathrm{c} 7 \mathrm{sc} 02181 \mathrm{j}$

rsc.li/chemical-science

\section{Rh-catalyzed aerobic oxidative cyclization of anilines, alkynes, and $\mathrm{CO} \dagger$}

\begin{abstract}
Xinyao Li, ${ }^{a}$ Jun Pan, ${ }^{a}$ Hao $\mathrm{Wu}^{\mathrm{a}}$ and Ning Jiao (D) *ab
Transition-metal-catalyzed oxidative $\mathrm{C}-\mathrm{H}$ cyclization of anilines has been an attractive and powerful strategy for the efficient construction of $\mathrm{N}$-heterocycles. However, primary and tertiary anilines are rarely employed in this strategy due to the relative instability with strong oxidants or the presence of three $\mathrm{C}-\mathrm{N}$ bonds. We describe here a novel Rh-catalyzed $\mathrm{C}-\mathrm{H}$ cyclization of a wide range of anilines with alkynes and $\mathrm{CO}$, using an aerobic oxidative protocol. Particularly, the simple primary anilines and readily prepared tertiary anilines could be easily converted to quinolin-2(1H)-ones, which are high value-added, biologically significant $\mathrm{N}$-heterocycles, via $\mathrm{C}-\mathrm{N}$ bond cleavage.
\end{abstract}

\section{Introduction}

$\mathrm{N}$-heterocyclic compounds are of great importance in pharmaceuticals and are also versatile building blocks for natural products, bioactive compounds, and drug synthesis. ${ }^{1}$ Transition metal-catalyzed oxidative $\mathrm{C}-\mathrm{H}$ cyclization of anilines and their derivatives has recently emerged as one of the most attractive and powerful strategies for the efficient construction of $\mathrm{N}$ heterocycles in terms of atom and step economy. ${ }^{2-6}$ In the past decades, $\mathrm{N}$-monosubstituted secondary ( $2^{\circ}$ amine) anilines and alkynes have been extensively used in this field with the assistance of stoichiometric oxidants in most cases (i, Scheme 1a). ${ }^{3,4}$ However, despite this significance, the preparation of $2^{\circ}$ anilines often requires tedious multi-steps because the tertiary $\left(3^{\circ}\right)$ amines would be mainly obtained by a traditional substitution reaction. In addition, the difficulty in removing the $\mathrm{R}$ group from the formed $\mathrm{N}$-heterocycles also limits their further transformation.

In contrast, primary $\left(1^{\circ}\right)$ and tertiary $\left(3^{\circ}\right)$ anilines are more readily available. However, only a few examples of oxidative cyclization reactions with $1^{\circ}$ anilines have been reported (ii, Scheme 1a), ${ }^{6}$ because of the instability of these primary anilines under strong oxidative conditions, and because they usually prefer to undergo acylation, hydroamination, and homocoupling. ${ }^{7}$ Moreover, the $\mathrm{C}-\mathrm{H}$ cyclization of alkynes with $3^{\circ}$ anilines which are easily prepared is still unknown because cleavage of one $\mathrm{C}-\mathrm{N}$ bond must be overcome in this process (iii, Scheme 1a). ${ }^{8}$ Most efforts in the field of $\mathrm{C}-\mathrm{N}$ bond cleavage of $3^{\circ}$ anilines

${ }^{a}$ State Key Laboratory of Natural and Biomimetic Drugs, Peking University, School of Pharmaceutical Sciences, Xue Yuan Rd. 38, Beijing 100191, China. E-mail: jiaoning@pku.edu.cn

${ }^{b}$ State Key Laboratory of Elemento-organic Chemistry, Nankai University, Weijin Rd. 94, Tianjin 300071, China

$\dagger$ Electronic supplementary information (ESI) available: Experimental details and spectral data. See DOI: 10.1039/c7sc02181j have been focused on amination, alkylation, and arylation transformations. ${ }^{9}$ Therefore, the practical oxidative $\mathrm{C}-\mathrm{H}$ cyclization of $1^{\circ}$ and $3^{\circ}$ anilines as stable chemicals to construct $\mathrm{N}$ heterocycles is very desirable but still a challenging issue. In addition, the transition metal-catalyzed $\mathrm{C}-\mathrm{H}$ cyclization of anilines with green and mild $\mathrm{O}_{2}$ as the oxidant $\mathrm{t}^{\mathbf{1 0 , 1 1}}$ is also very desirable.

Herein, using an aerobic oxidative strategy, we report an efficient $\mathrm{Rh}$-catalyzed $\mathrm{C}-\mathrm{H}$ cyclization of simple anilines, alkynes, and CO (Scheme 1b). The advantages of this protocol are threefold: (1) a wide range of anilines are significantly employed in this cyclization protocol and this enables new direct routes to $\mathrm{N}-\mathrm{H}$ and $\mathrm{N}-\mathrm{R}$ quinolin-2(1H)-ones, which

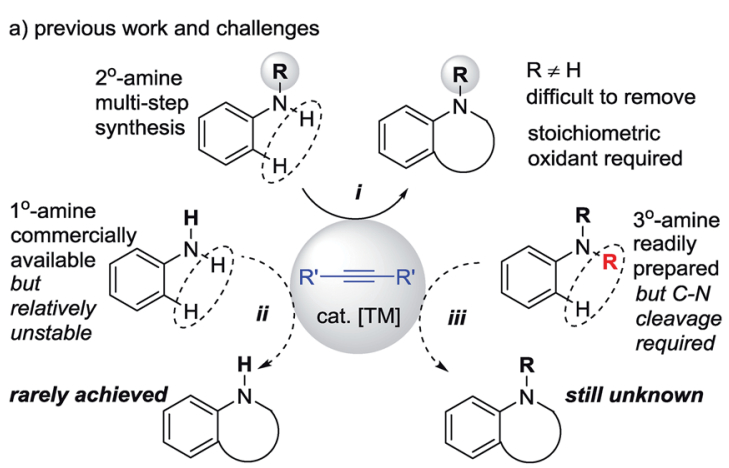

b) This work: Rh-catalyzed aerobic oxidative annulation of various anilines

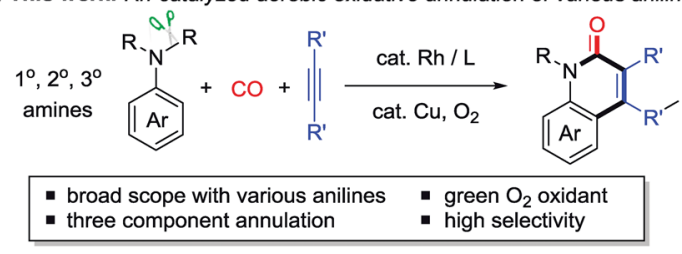

Scheme 1 Aerobic oxidative annulation strategies to construct heterocycles. 
represent an important class of fused heterocyclic compounds found in many alkaloids. ${ }^{12,13}$ To the best of our knowledge, this chemistry is the first straightforward transformation of primary anilines to $\mathrm{N}-\mathrm{H}$ quinolin-2 $(1 H)$-ones, whose synthesis usually suffers from multi-step synthesis including protection and deprotection processes..$^{13}$ In addition, the intermolecular $\mathrm{C}-\mathrm{H}$ cyclization of tertiary anilines with alkynes through $\mathrm{C}-\mathrm{N}$ cleavage was still unknown until this case. (2) $\mathrm{O}_{2}$ is successfully utilized as the sacrificial oxidant for the aerobic oxidative cyclizations in efficient ways to fulfill the requirements of green chemistry. ${ }^{10,11}$ (3) In contrast to the well-known two component aerobic oxidative cyclizations for $\mathrm{N}$-heterocycles such as indoles, ${ }^{3}$ this chemistry provides a three component cyclization approach to $\mathrm{N}$ heterocycles with $\mathrm{CO}$, which has been used as a prominent C1 synthon in organic synthesis. ${ }^{\mathbf{1 4 , 1 5}}$

\section{Results and discussion}

We initially chose $N, N$-dimethylaniline (1a), simple aniline (2a), $N$-methylaniline (3a), and dec-5-yne (4a) as model substrates for the investigation of $\mathrm{C}-\mathrm{H}$ cyclization with $\mathrm{CO}$ (Table 1). Considering the simple anilines could not survive well with strong oxidant, we started the screening with $\mathrm{O}_{2}$ as the oxidant under atmospheric pressure. Interestingly, we were excited that the reaction of $\mathbf{1 a}$ catalyzed by $\left[\mathrm{Rh}(\mathrm{CO})_{2} \mathrm{Cl}\right]_{2}$ with a catalytic amount of $\mathrm{Cu}(\mathrm{OPiv})_{2}(10 \mathrm{~mol} \%)$ afforded $\mathrm{N}$ -

Table 1 Optimization for the reaction of $N, N$-dimethylaniline (1a), aniline (2a), and $N$-methylaniline (3a) with dec-5-yne (4a) ${ }^{a}$
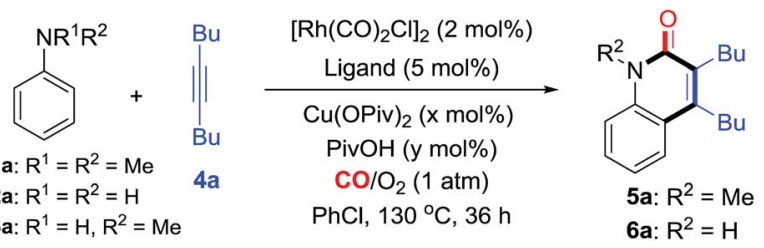

\begin{tabular}{lllllll}
\hline Entry & Aniline & Ligand & $x$ & $y$ & $\mathrm{CO} / \mathrm{O}_{2}$ & Yield $^{b}(\%)$ \\
\hline 1 & $\mathbf{1 a}$ & - & 10 & 100 & $4 / 1$ & $\mathbf{5 a , 2 0}$ \\
2 & $\mathbf{1 a}$ & - & 10 & 100 & $1 / 2$ & $\mathbf{5 a}, 34$ \\
3 & $\mathbf{1 a}$ & SIMes & 10 & 100 & $1 / 2$ & $\mathbf{5 a}, 36$ \\
4 & $\mathbf{1 a}$ & Xantphos & 10 & 100 & $1 / 2$ & $\mathbf{5 a}, 41$ \\
5 & $\mathbf{1 a}$ & BINAP & 10 & 100 & $1 / 2$ & $\mathbf{5 a}, 46$ \\
6 & $\mathbf{1 a}$ & dppp & 10 & 100 & $1 / 2$ & $\mathbf{5 a}, 46$ \\
7 & $\mathbf{1 a}$ & dppb & 10 & 100 & $1 / 2$ & $\mathbf{5 a}, 49$ \\
8 & $\mathbf{1 a}$ & dppb & 10 & 100 & $2 / 1$ & $\mathbf{5 a}, 60$ \\
9 & $\mathbf{1 a}$ & dppb & 20 & 30 & $2 / 1$ & $\mathbf{5 a}, 74(72)^{c}$ \\
10 & $\mathbf{1 a}$ & dppb & 0 & 30 & $2 / 1$ & $\mathbf{5 a}, \mathrm{trace}^{c}$ \\
11 & $\mathbf{2 a}$ & - & 10 & 100 & $4 / 1$ & $\mathbf{6 a},(67)^{c}$ \\
12 & $\mathbf{3 a}$ & - & 10 & 100 & $4 / 1$ & $\mathbf{5 a},(85)^{c}$
\end{tabular}

${ }^{a}$ Reaction conditions: aniline $1 \mathrm{a}-3 \mathrm{a}(0.3 \mathrm{mmol})$, alkyne $4 \mathrm{a}(0.45 \mathrm{mmol})$, $\mathrm{Rh}$ catalyst $(2 \mathrm{~mol} \%)$, ligand (5 $\mathrm{mol} \%), \mathrm{Cu}$ catalyst $(x \mathrm{~mol} \%)$, and additive $(y \mathrm{~mol} \%)$ in $\mathrm{PhCl}(2 \mathrm{~mL})$ under $1 \mathrm{~atm} \mathrm{CO} / \mathrm{O}_{2}(\mathrm{v} / \mathrm{v}, 1 \mathrm{~atm})$ at $130{ }^{\circ} \mathrm{C}$ for 36 h. ${ }^{b}$ Yields were determined by GC analysis. ${ }^{c}$ Isolated yields.
methyl-quinolin-2(1H)-one 5a in $20 \%$ yield (entry 1 , Table 1 ). Changing the mixed gas ratio and screening ligands demonstrated that dppb performed best under a mixed gas of $\mathrm{CO} / \mathrm{O}_{2}=2: 1$, giving the product 5a in $60 \%$ yield (entries 28 ). Finally, 5a was obtained in $72 \%$ yield under the optimized conditions with a catalytic amount of $\mathrm{PivOH}$ as the additive (condition A, entry 9, Table 1). Control experiments indicated that the $\mathrm{Cu}$ and $\mathrm{Rh}$ catalysts were both essential for this transformation (see entry 10, Tables 1 and $\mathrm{S} 1$ in the ESI $\dagger$ for details). Meanwhile, the $\mathrm{C}-\mathrm{H}$ cyclization with the primary aniline 2a was also investigated. To our delight, under similar conditions (condition B, entry 11, Table 1), aniline (2a) was smoothly converted into the corresponding $\mathrm{N}-\mathrm{H}$ quinolin-2(1H)-one 6 a in $67 \%$ yield. Finally, under the optimized conditions (condition $\mathrm{B}$, entry 12 , Table 1 ), the reaction of $N$-methylaniline (3a) produced 5 a in $85 \%$ yield.

With the established aerobic oxidative conditions in hand, we initially examined the scope of tertiary anilines $\mathbf{1}$ with alkynes $\mathbf{4}$ under condition A (Table 2). The reaction proved to be tolerant of different substitution patterns on the aromatic core. In general, both electron-donating and electron-withdrawing substituents of anilines were well tolerated under these conditions (5a-h). Anilines substituted with halogens (F, Cl, and $\mathrm{Br}$ ) afforded the corresponding quinolin-2 $(1 H)$-ones in moderate to good yields (5d-f), which could be used for further functionalization. In addition, other alkynes were compatible to give the expected products under condition A in moderate efficiencies

Table 2 Substrate scope of tertiary anilines ${ }^{a}$

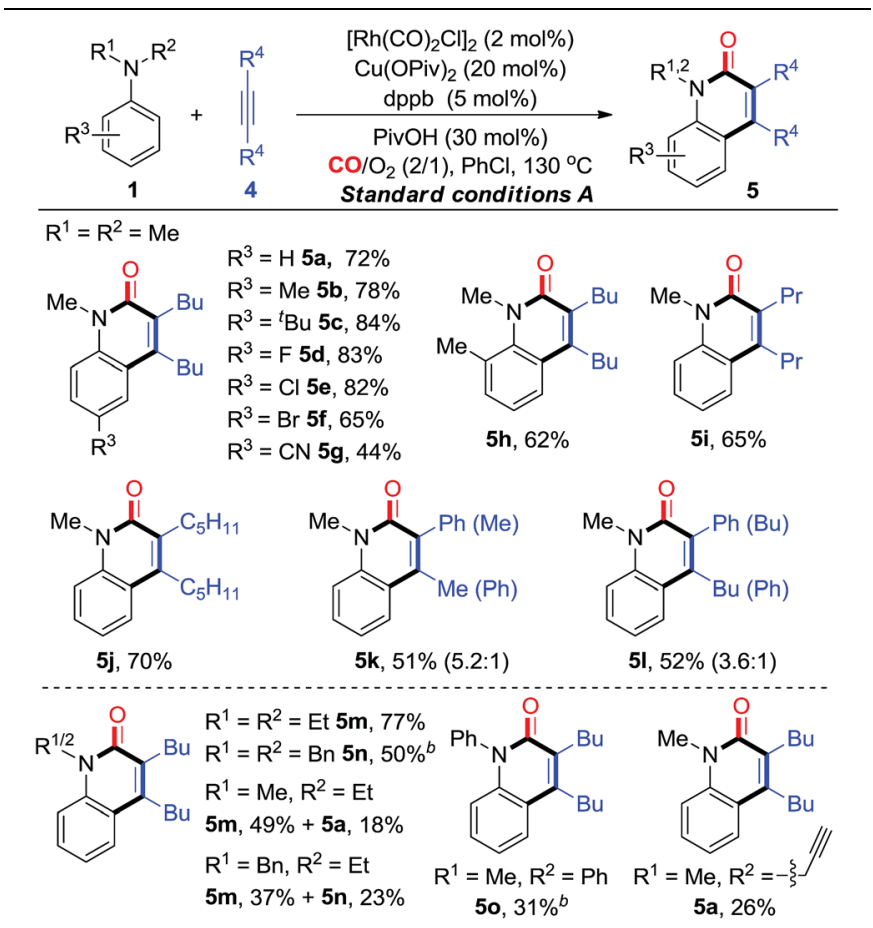

${ }^{a}$ Condition A: see entry 9, Table 1 . Isolated yields. ${ }^{b} 4$ (2 equiv.) was employed. 
(5i and $\mathbf{j}$ ). The asymmetrical aryl alkyl alkynes were also suitable for this reaction, affording the corresponding products in good yields with moderate regioselectivity (5k and $\mathbf{l}$ ).

Furthermore, we investigated the scope of $\mathrm{N}, \mathrm{N}$-dialkylanilines to determine whether $N$-ethyl and $N$-benzyl groups were compatible (5m and $\mathbf{n}$ ). Interestingly, when $N$-ethyl- $N$-methylaniline was treated with $\mathbf{4 a}$, two products $5 \mathbf{m}$ and $5 \mathbf{a}$ were obtained in $49 \%$ and $18 \%$ yields, respectively. $N$-benzyl- $N$ ethylaniline was smoothly converted into the products $5 \mathbf{m}$ and 5n in $37 \%$ and $23 \%$ yields, respectively. It is worth noting that $N$ methyl- $N$-(prop-2-yn-1-yl)-aniline provided 5a, while $N$-methyl$N$-phenylaniline afforded $\mathbf{5 0}$ as the sole product in $31 \%$ yield, which could not be produced from diphenylamine under condition $\mathrm{B}$. The activation of $N$ groups has the order of $\mathrm{Me}>\mathrm{Bn}$ $>$ Et $>\mathrm{Ph}$, indicating that the less sterically hindered alkyl group is much more facile for cleavage.

On the basis of the optimization studies, we then evaluated the scope and generality of primary anilines in this transformation (Table 3). In general, primary anilines containing electron-rich/deficient functional groups reacted smoothly to give $\mathrm{N}-\mathrm{H}$ quinolin-2 $(1 H)$-ones $\mathbf{6 a - k}$ in moderate to good yields. Furthermore, a series of $o$-substituents can be compatible and the corresponding quinolin-2 $(1 H)$-ones were obtained in 40 $79 \%$ yields $(\mathbf{6} \mathbf{-}-\mathbf{q})$. The annulation proceeded well with disubstituted aniline (6r). The protocol could also be applied to olefin-containing aniline, thereby allowing further derivatization of the formed quinolin- $2(1 H)$-one $\mathbf{6 s}$. When the reaction was carried out using a heterocyclic amine, the desired product

Table 3 Substrate scope of primary anilines ${ }^{a}$

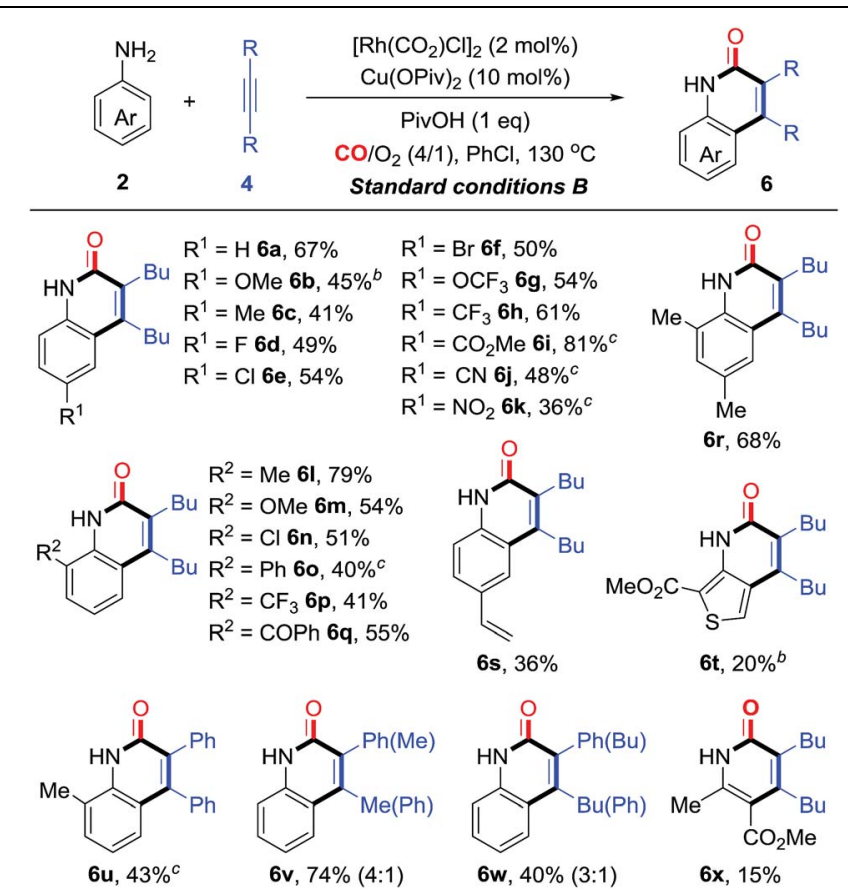
${ }^{a}$ Condition B: see entry 11, Table 1 . Isolated yields. ${ }^{b} 4$ (3 equiv.) was
employed. $^{c} 2$ (2 equiv.) and 4 (1 equiv.) were employed. 6t was obtained in $20 \%$ yield. Additionally, a diarylalkyne reacted smoothly to give the corresponding product $\mathbf{6 u}$ in moderate yield. For the unsymmetrical aryl alkyl alkyne, its annulations gave the desired compounds (6v and $\mathbf{w}$ ) in $35-40 \%$ yields with moderate regioselectivity. Interestingly, multisubstituted pyridin-2(1H)-one $\mathbf{6 x}$ could be constructed from the enamine through this synthetic strategy albeit in low yield (15\%, Table 3 ).

At this point, a range of secondary anilines 3 were also fully compatible under the conditions B (Table 4). A variety of $N$ methylanilines bearing electron-donating or electronwithdrawing substituents on the phenyl ring underwent the annulation to afford the corresponding quinolin-2( $1 H)$-ones $(\mathbf{5 c}-\mathbf{g}$ and $\mathbf{5 p}-\mathbf{s})$ in moderate to excellent yields. For more broadly synthetic interests, various functionalized groups, such as halides, free carboxylic acid, esters, and nitriles were tolerated. In the case of $N$-alkyl substituted anilines with a PMB group, even with a cyclopropyl group, the desired quinolin$2(1 H)$-ones (5t and $\mathbf{u}$ ) were obtained successfully. Interestingly, tetrahydroquinoline, tetrahydro- $1 H$-benzo $[b]$ azepine, and dihydrodibenzooxazepines smoothly led to the more complex polyheterocyclic compounds $(\mathbf{5 v}-\mathbf{x})$ in moderate to good yields, which are usually found in natural products as the core structural motif and show possible bioactivity. Diaryl-substituted alkynes also were proved to be very suitable to such annulations, thus yielding the corresponding products $5 \mathbf{y}-\mathbf{z}$ in $62 \%$ yields. The unsymmetrical alkynes were also suitable for this reaction, affording the corresponding products in high yields with moderate regioselectivity (5k and $\mathbf{l}$ ).

Table 4 Substrate scope of secondary anilines ${ }^{a}$
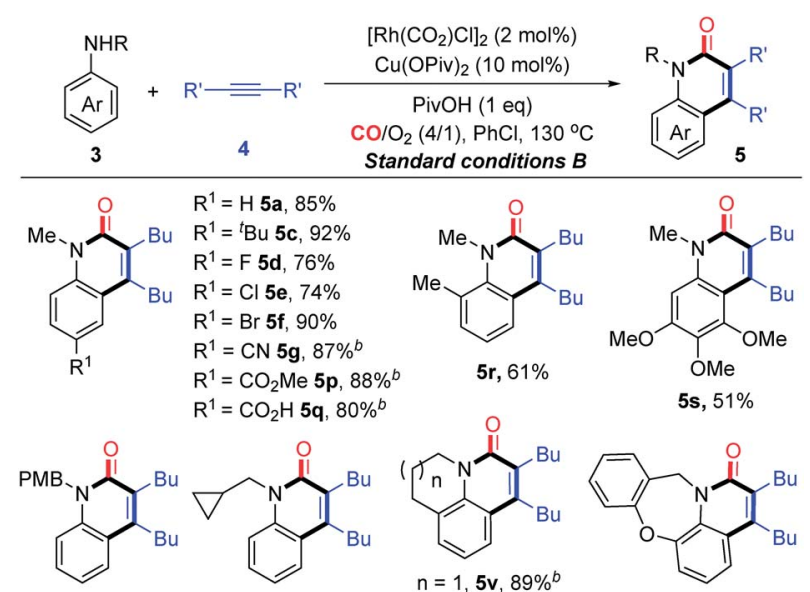

5t, $65 \%$

5 u, $82 \%$ $n=2,5 w, 85 \%$

$5 \mathbf{x}, 52 \%$

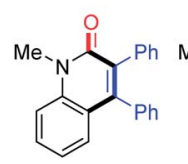

$5 y, 62 \%$

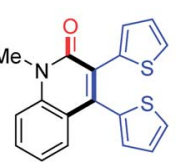

$5 z, 62 \%$

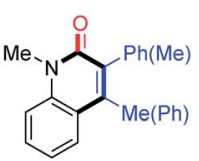

5k, $81 \%(3.5: 1)$

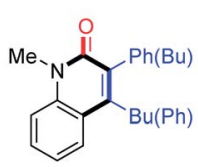

5I, $82 \%(3: 1)$
${ }^{a}$ Condition B: see entry 12 , Table 1 . Isolated yields. ${ }^{b} 3(0.6 \mathrm{mmol})$ and 4 (0.3 mmol) were employed. 
After having proven a wide substrate scope tolerance, this protocol was further applied to the synthesis of significant intermediates and complex bioactive molecules. To be specific, a mixture of $1 \mathbf{a}$ and $3 \mathbf{a}$ can be converted into the sole product $5 \mathbf{a}$ in good yields (Scheme 2A), which demonstrates that the secondary aniline could also be tolerated by the protocol. Notably, compound 7, known as a potential p38aMAP kinase inhibitor, ${ }^{16}$ can be directly constructed in satisfactory yield through the protocol (Scheme 2B). Additionally, the significant intermediate 9, which can undergo further derivatization to obtain supramolecular catalysts, can be directly obtained through only one step from the corresponding primary aniline 8 under the current standard condition B (Scheme 2C). In contrast, 9 was reported to be prepared through six steps through Larock's method including the intermediacy of $o$-iodoamide. ${ }^{17}$ The current protocol could be applied to the late-stage construction of $\alpha 4$ integrin inhibitory 15 from aniline $3 \mathrm{~m}$ and the prepared alkyne 14, in $40 \%$ total yield with four steps (Scheme 2D), which has potential utility in medicinal chemistry. ${ }^{18}$

To gain some preliminary understanding of the reaction mechanism, several experiments were carried out under the standard conditions. An isotopic labelling experiment was carried out on the model reaction of 1a or 3a with $4 \mathbf{a}$ under standard conditions, and a H/D exchange of $6 \%$ in product 5 a was found with the addition of deuterated water, thereby implicating a reversible cyclometalation mode [eqn (1)]. In addition, the intermolecular KIE for the annulation reaction was determined to be $k_{\mathrm{H}} / k_{\mathrm{D}}=1.13$ for $1 \mathrm{a}$ and 1.04 for $3 \mathrm{a}$,
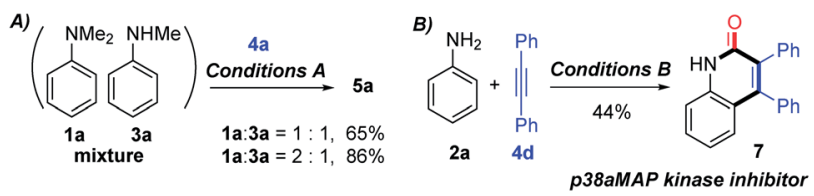

C)
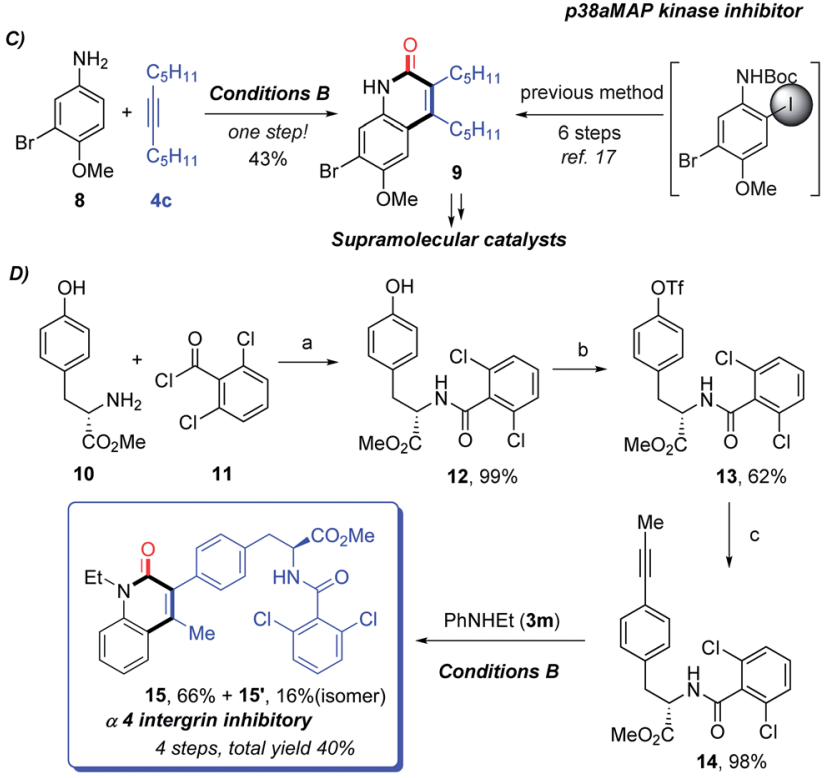

Scheme 2 Further application of the protocol to synthesize significant intermediates and complex bioactive molecules. (a) $\mathrm{Et}_{3} \mathrm{~N}, \mathrm{DCM}, \mathrm{RT}$, 2 h, 99\%; (b) $\mathrm{Tf}_{2} \mathrm{O}, \mathrm{Py}, \mathrm{DCM}, \mathrm{RT}, 1 \mathrm{~h}, 62 \%$; (c) $\mathrm{MeC} \equiv \mathrm{CTMS}, \mathrm{Pd}(\mathrm{dppf}) \mathrm{Cl}_{2}$, Cul, iPr ${ }_{2} \mathrm{NEt}, \mathrm{DMF}, 90^{\circ} \mathrm{C}, 24 \mathrm{~h}, 98 \%$.

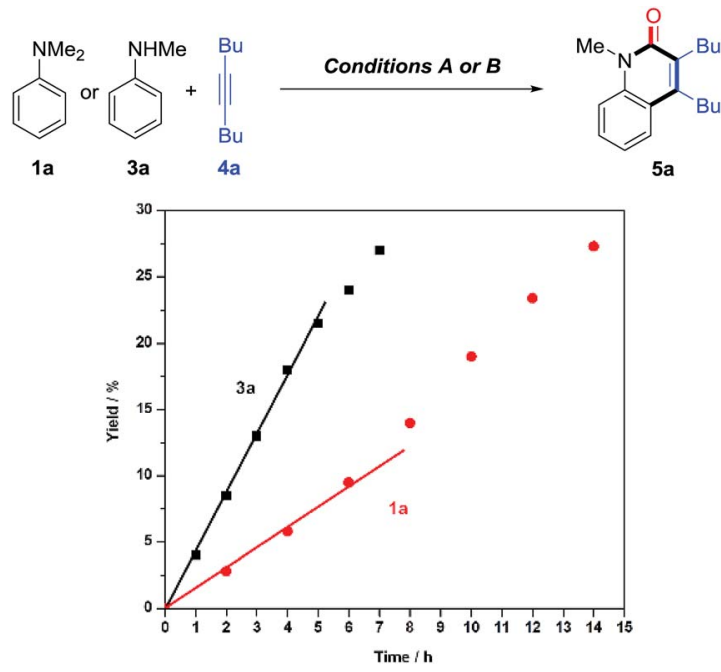

Fig. 1 Annulation profile under conditions A or B: red circles for 1a; black squares for $3 a$.

indicating that $\mathrm{C}\left(\mathrm{sp}^{2}\right)-\mathrm{H}$ bond cleavage should not be involved in the rate-determining step of the catalytic cycle [eqn (2)].

Control experiments showed that no desired product was observed in the absence or presence of $\mathrm{CO}$, when formylated aniline $\mathbf{1 6}$ was treated with $\mathbf{4 a}$ [eqn (3)]. These results indicate that the formation of formylated aniline is not involved in this process. In addition, carbamic chloride $\mathbf{1 7}$ also did not give the expected product $\mathbf{5 a}$ through oxidative addition in the presence of Rh catalyst [eqn (4)]. It is worth noting that deuteration of $N$ methyl groups results in a significant KIE, $k_{\mathrm{H}} / k_{\mathrm{D}}=2.53$ for intramolecular KIE and $k_{\mathrm{H}} / k_{\mathrm{D}}=2.00$ for intermolecular KIE, indicating that $\mathrm{C}\left(\mathrm{sp}^{3}\right)-\mathrm{H}$ bond cleavage might be involved in the rate-determining step for tertiary anilines [eqn (5) and (6)]. Besides, when $N, N^{\prime}$-dibenzylaniline was employed, a $5 \%$ yield of benzaldehyde (18) was detected along with the expected product [eqn (7)]. This by-product is likely to be generated from the imine intermediate formed in situ through the oxidation of $\mathrm{C}\left(\mathrm{sp}^{3}\right)-\mathrm{H}$ at the ortho position of the $\mathrm{N}$ atom. The kinetic experiments show that the initial reaction rate of $3 \mathbf{a}$ is about three times that of 1a (Fig. 1), implying that the $\mathrm{C}-\mathrm{N}$ bond cleavage of $1 \mathbf{a}$ was the key step.

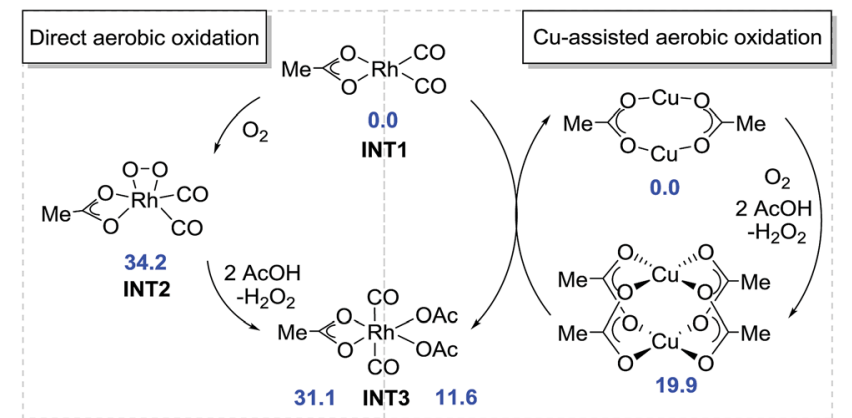

Fig. 2 Direct and Cu-assisted aerobic oxidation of $\mathrm{Rh}(\mathrm{I})$. 
Based on our preliminary mechanistic studies, we conducted a density functional theory (DFT) investigation into the Rh-catalyzed assembly of anilines, alkynes, and CO for quinolin-2(1H)-one construction to better understand the mechanism of this transformation. ${ }^{19}$ The $t \mathrm{Bu}$ groups in acid and $n \mathrm{Bu}$ groups in alkyne were replaced by methyl groups to save computational time but without sacrificing credibility. Initially, the direct aerobic oxidation of $\mathrm{Rh}(\mathrm{I})$ to $\mathrm{Rh}$ (III) is calculated to be endergonic by $31.1 \mathrm{kcal} \mathrm{mol}^{-1}$ and the generation of the intermediate INT2 requires a free energy of $34.2 \mathrm{kcal} \mathrm{mol}^{-1}$, indicating that the direct aerobic oxidation of $\mathrm{Rh}(\mathrm{I}$ ) is disfavored (Fig. 2). However, $\mathrm{Rh}(\mathrm{I})$ can be easily oxidized to $\mathrm{Rh}$ (III) by $\mathrm{Cu}(\mathrm{II})$, which is slightly endergonic by $11.6 \mathrm{kcal} \mathrm{mol}^{-1}$. The formed $\mathrm{Cu}(\mathrm{I})$ can also be oxidized to $\mathrm{Cu}(\mathrm{II})$ using $\mathrm{O}_{2}$ in the presence of carboxylic acid, with a free energy of $19.9 \mathrm{kcal} \mathrm{mol}^{-1}$. This is consistent with the experimental observation that the $\mathrm{Cu}$ catalyst plays a pivotal role in the transformation.

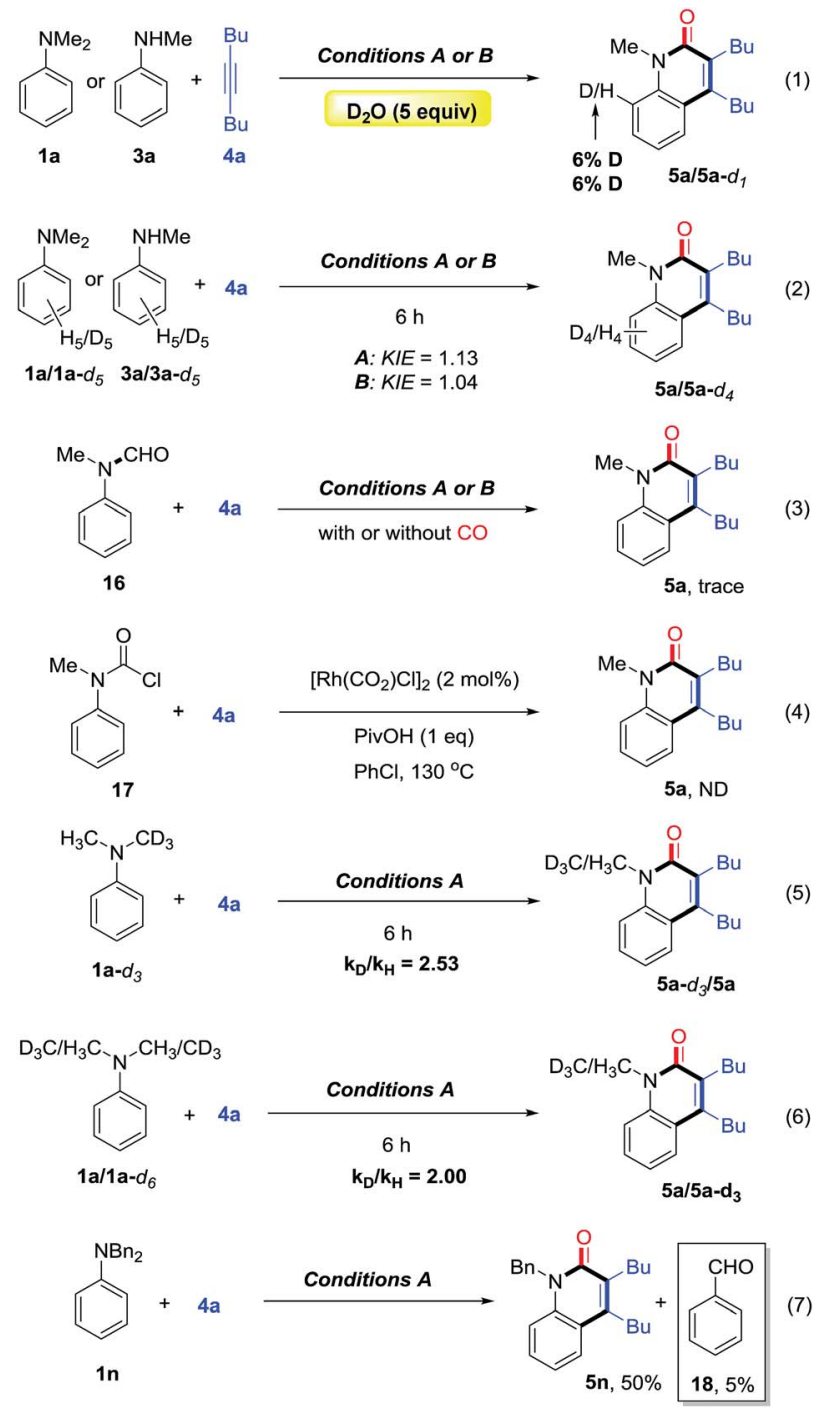

The $\mathrm{C}-\mathrm{N}$ bond cleavage process with tertiary aniline is interesting. On the basis of the previous results and our primary experiments, ${ }^{\mathbf{9}, 20}$ the calculations showed that the
$\mathrm{Cu}(\mathrm{II})$ species are capable of oxidizing tertiary aniline through single electron transfer (SET) and hydrogen atom transfer (HAT) pathways to give the iminium-type intermediate, which requires a free energy of $8.8 \mathrm{kcal} \mathrm{mol}^{-1}$ (Fig. 3). The formed iminium-type intermediate is then facilely hydrolyzed to the secondary aniline by the elimination of aldehyde as an exergonic process by $34.9 \mathrm{kcal} \mathrm{mol}^{-1}$. The $\mathrm{Cu}$ (I) catalyst is then reoxidized by oxygen to form the $\mathrm{Cu}$ (II) species in the presence of carboxylic acid, with a free energy of $19.9 \mathrm{kcal} \mathrm{mol}^{-1}$.

When the Rh(III) species INT3 is formed, the coordination of the secondary aniline $\mathbf{3 a}$ to $\mathrm{Rh}$ (III) species is exergonic by $7.9 \mathrm{kcal} \mathrm{mol} \mathrm{m}^{-1}$ to give the stable complex INT4 that undergoes further dehydrogenation with the release of HOAc to furnish INT5 endergonicly (Fig. 3). Then, the consequent insertion of $\mathrm{CO}$ from Rh to aniline takes place through the transition state TS1 with an activation free energy of $22.1 \mathrm{kcal}$ $\mathrm{mol}^{-1}$ to afford INT6. The following $\mathrm{H}$-abstraction through the transition state $\mathbf{T S} 2$ requires an activation free energy of only $1.8 \mathrm{kcal} \mathrm{mol}^{-1}$ to afford the much more stable INT7. After the ligand exchange of INT7 with alkyne 4, the formed rhodacycle complex INT8 undergoes alkyne insertion through two stepwise pathways. When the C(Ar)-C(alkyne) bond was formed preferentially, it required an activation free energy of $20.0 \mathrm{kcal} \mathrm{mol}^{-1}$ to afford the seven-membered rhodacycle INT9. Finally, the reductive elimination is facile through TS4 with an energetic barrier of only $5.3 \mathrm{kcal} \mathrm{mol}^{-1}$, delivering the product 5 exogonicly, whilst regenerating the $\mathrm{Rh}(\mathrm{I})$ catalyst. Alternatively, when the $\mathrm{C}(\mathrm{CO})-\mathrm{C}($ alkyne) bond was formed preferentially, the barrier to the transition state TS5 was high at $31.6 \mathrm{kcal} \mathrm{mol}^{-1}$, which is $11.6 \mathrm{kcal} \mathrm{mol}^{-1}$ higher than TS3, although the consequent reductive elimination occurs almost without a barrier to provide the product 5. The delivered Rh(I) species INT1 is reoxidized to the Rh(III) complex INT3 in the presence of $\mathrm{Cu}$ (II). Reviewing the whole energy profile, we found that the CO insertion and alkyne insertion in the $\mathrm{Rh}(\mathrm{III})$ species are the key processes for this transformation.

This synthetic strategy can be efficiently catalyzed by the Rh-catalysis system. However, a Pd-catalysis system proved ineffective experimentally. Accordingly, the energy profile of the unreactive Pd-catalysis system was also calculated for comparison (Fig. 4, see the ESI $\dagger$ for details). It was found that the Pd-catalysis system suffers from a high energetic barrier of $38.3 \mathrm{kcal} \mathrm{mol}^{-1}$ (TS9) in the alkyne insertion process due to the unstable quadridentate fashion of the $\mathrm{Pd}$ complex, although the CO insertion is facile with an energetic barrier of only $13.6 \mathrm{kcal} \mathrm{mol}^{-1}$ (TS7). This is qualitatively consistent with the experimental observation. In addition, an Ir-catalysis system has been employed in a recent report. ${ }^{4 c}$ The current calculation study indicated that the CO insertion catalyzed by the Ir complex suffers from an activation free energy of $28.3 \mathrm{kcal} \mathrm{mol}^{-1}$, which is $6.2 \mathrm{kcal} \mathrm{mol}^{-1}$ higher than that of the Rh-catalysis, once again in agreement with the experimental demand of 30 atm CO for Ir-catalysis. 

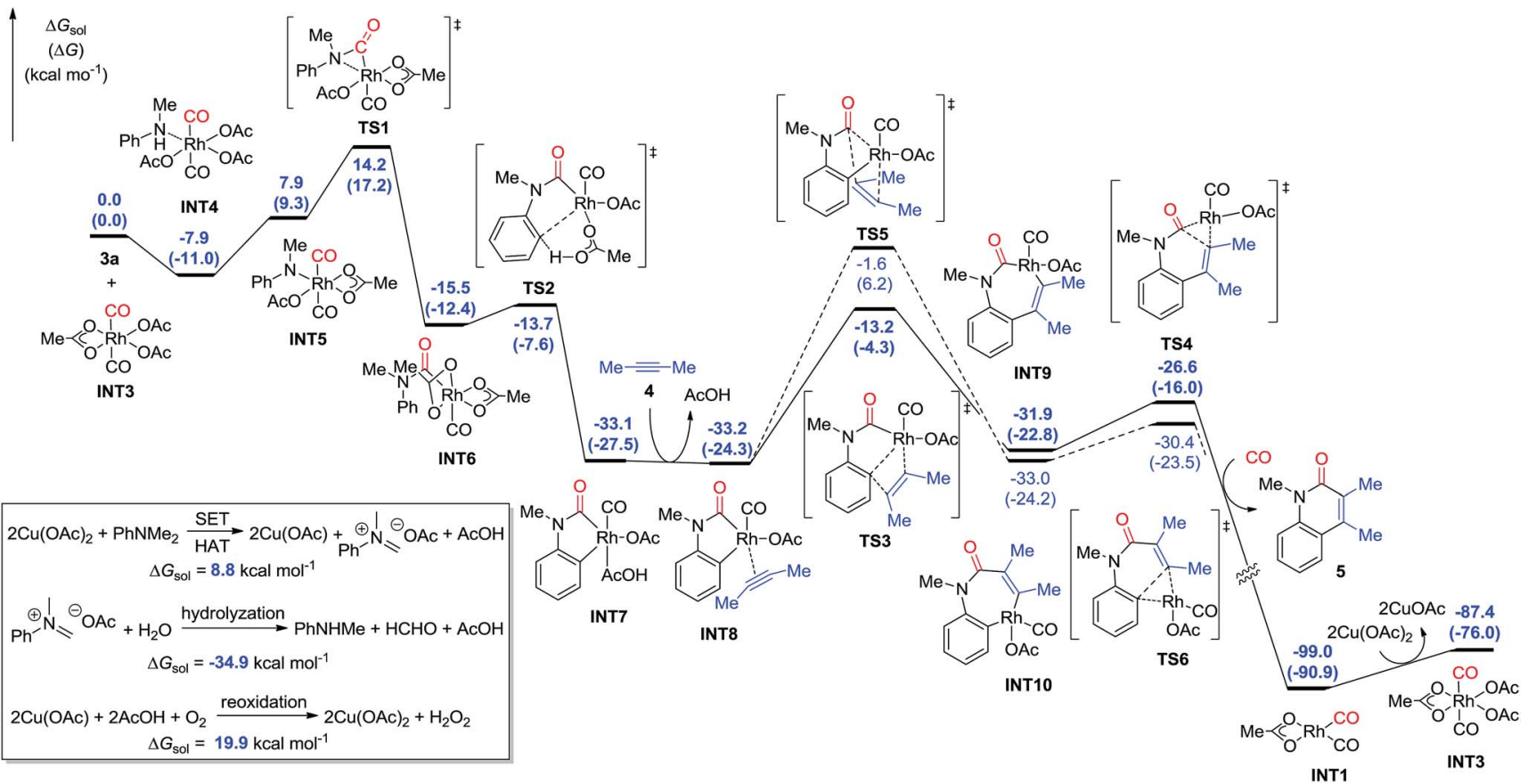

Fig. 3 DFT-computed energy profiles for quinolin-2(1H)-one construction through Rh-catalyzed assembly of anilines, alkynes, and CO. The energies discussed are the Gibbs free energies in $\mathrm{PhCl}\left(\Delta G_{\mathrm{sol}}\right)$. The numbers in the parentheses are the Gibbs free energies in the gas-phase ( $\left.\Delta G\right)$.

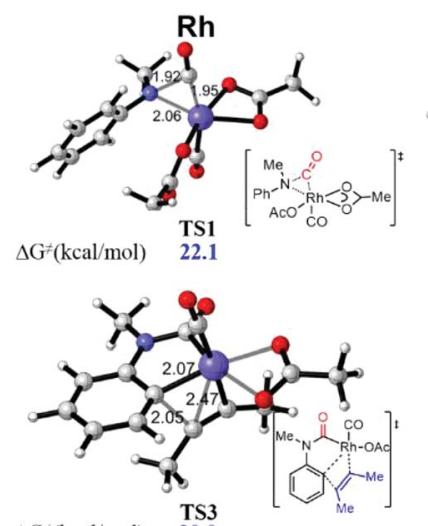

$\Delta \mathrm{G}^{+}(\mathrm{kcal} / \mathrm{mol}) \quad 20.0$

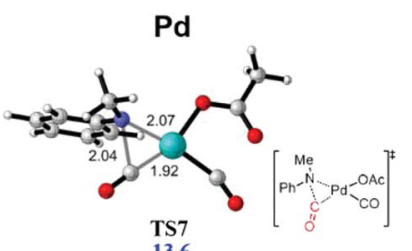

TS7
13.6

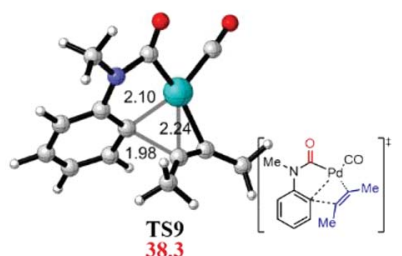

Fig. 4 DFT-computed transition state structures of $\mathrm{CO}$ insertion and alkyne insertion in Rh and Pd catalysis systems.

\section{Conclusions}

In conclusion, a wide variety of anilines, especially simple primary and tertiary anilines, were successfully employed in intermolecular $\mathrm{C}-\mathrm{H}$ cyclization with alkynes and $\mathrm{CO}$. This novel protocol using Rh-catalysis provides a direct approach to $\mathrm{N}-\mathrm{H} / \mathrm{N}$-substituted quinolin-2(1H)-ones. The readily available anilines and the operationally simple conditions under 1 atm mixture of $\mathrm{CO}$ and $\mathrm{O}_{2}$ make this protocol very practical, green, and sustainable. This chemistry provides a direct route to quinolin-2(1H)-ones, which are biologically significant $\mathrm{N}$-heterocycles and useful building blocks in organic synthesis. DFT calculations suggest that the relay of CO insertion and alkyne insertion in Rh-catalysis are disclosed as the

key processes, while the unreactive Pd-catalysis suffers from a high energetic barrier in the alkyne insertion process due to the unstable quadridentate fashion of the Pd complex. Further applications of this transformation are ongoing in our laboratory.

\section{Acknowledgements}

Financial support from National Basic Research Program of China (973 Program) (grant No. 2015CB856600), National Natural Science Foundation of China (No. 21325206, 21632001), National Young Top-notch Talent Support Program, and Peking University Health Science Center (No. BMU20160541) is greatly appreciated. We thank Lingsheng $\mathrm{Ai}$ in this group for reproducing the results for $\mathbf{5 m}, \mathbf{6 f}$, and $\mathbf{5 v}$.

\section{Notes and references}

1 (a) T. Eicher and S. Hauptmann, The Chemistry of Heterocycles: Structure, Reactions, Syntheses, and Applications, 2nd edn, Wiley-VCH, Weinheim, 2003; (b) G. Jones, Comprehensive Heterocyclic Chemistry II, ed. A. R. Katritzky, C. W. Rees and E. F. V. Scriven, Pergamon Press, New York, 1996.

2 For reviews on $\mathrm{C}-\mathrm{H}$ annulations, see: (a) L. Ackermann, Acc. Chem. Res., 2014, 47, 281; (b) G. Song, F. Wang and X. Li, Chem. Soc. Rev., 2012, 41, 3651; (c) T. Satoh and M. Miura, Chem.-Eur. J., 2010, 16, 11212; (d) M. Gulñas and J. L. MascareÇas, Angew. Chem., Int. Ed., 2016, 55, 11000; (e) N. Yoshikai and Y. Wei, Asian J. Org. Chem., 2013, 2, 466. 3 For examples of $\mathrm{N}$-heterocycle synthesis from anilines and derivatives with alkynes, see: (a) D. R. Stuart, M. Bertrand- 
Laperle, K. M. N. Burgess and K. Fagnou, J. Am. Chem. Soc., 2008, 130, 16474; (b) D. R. Stuart, P. Alsabeh, M. Kuhn and K. Fagnou, J. Am. Chem. Soc., 2010, 132, 18326; (c) M. P. Huestis, L. Chan, D. R. Stuart and K. Fagnou, Angew. Chem., Int. Ed., 2011, 50, 1338; (d) C. Wang, H. Sun, Y. Fang and Y. Huang, Angew. Chem., Int. Ed., 2013, 52, 5795; (e) D. Zhao, Z. Shi and F. Glorius, Angew. Chem., Int. Ed., 2013, 52, 12426; (f) L. Ackermann and A. V. Lygin, Org. Lett., 2012, 14, 764; $(g)$ J. Chen, G. Song, C.-L. Pan and X. Li, Org. Lett., 2010, 12, 5426; (h) S. Cai, K. Yang and D. Z. Wang, Org. Lett., 2014, 16, 2606; ( $i$ ) P. Tao and Y. Ji, Chem. Commun., 2014, 50, 7367; (j) Y. Kim and S. Hong, Chem. Commun., 2015, 51, 11202.

4 For examples of N-heterocycle synthesis from the threecomponent cyclization of secondary anilines with alkynes and CO (1-30 atm), using a stoichiometric amount of BQ or copper salt as the oxidant, see: (a) J. Chen, K. Natte, A. Spannenberg, H. Neumann, M. Beller and X.-F. Wu, Chem.-Eur. J., 2014, 20, 14189; (b) X. Y. Li, X. W. Li and N. Jiao, J. Am. Chem. Soc., 2015, 137, 9246; (c) F. Zhu, Y. Li, Z. Wang and X.-F. Wu, Adv. Synth. Catal., 2016, 358, 3350; (d) J. Chen, J.-B. Feng, K. Natte and X.-F. Wu, Chem.-Eur. J., 2015, 21, 16370.

5 For examples of $\mathrm{N}$-heterocycle synthesis from other $\mathrm{N}$ containing substrates: (a) R. Bernini, G. Fabrizi, A. Sferrazza and S. Cacchi, Angew. Chem., Int. Ed., 2009, 48, 8078; (b) S. Würtz, S. Rakshit, J. J. Neumann, T. Dröge and F. Glorius, Angew. Chem., Int. Ed., 2008, 47, 7230; (c) X. Xu, Y. Liu and C.-M. Park, Angew. Chem., Int. Ed., 2012, 51, 9372; (d) T. K. Hyster and T. Rovis, Chem. Sci., 2011, 2, 1606; (e) T. K. Hyster and T. Rovis, J. Am. Chem. Soc., 2010, 132, 10565; ( $f$ ) L. Ackermann, A. V. Lygin and N. Hofmann, Angew. Chem., Int. Ed., 2011, 50, 6379; (g) L. Ackermann, A. V. Lygin and N. Hofmann, Org. Lett., 2011, 13, 3278; (h) Z. Shi, B. Zhang, Y. Cui and N. Jiao, Angew. Chem., Int. Ed., 2010, 49, 4036; (i) Y. Wei, I. Deb, N. Yoshikai, J. Am. Chem. Soc., 2012, 134, 9098; (j) L. Ackermann, L. Wang and A. V. Lygin, Chem. Sci., 2012, 3, 177; $(k)$ L. Wang and L. Ackermann, Org. Lett., 2013, 15, 176; (l) S. Y. Hong, J. Jeong and S. Chang, Angew. Chem., Int. Ed., 2017, 56, 2408; $(m)$ K. Alex, A. Tillack, N. Schwarz and M. Beller, Angew. Chem., Int. Ed., 2008, 47, 2304; (n) M. Shen, B. E. Leslie and T. G. Driver, Angew. Chem., Int. Ed., 2008, 47, 5056; (o) Á. M. Martínez, J. Echavarren, I. Alonso, N. Rodríguez, R. G. Arrayás and J. C. Carretero, Chem. Sci., 2015, 6, 5802.

6 (a) Z. Shi, C. Zhang, S. Li, D. Pan, S. Ding, Y. Cui and N. Jiao, Angew. Chem., Int. Ed., 2009, 48, 4572; (b) G. Zhang, H. Yu, G. Qin and H. Huang, Chem. Commun., 2014, 50, 4331.

7 (a) G. Choudhary and R. K. Peddinti, Green Chem., 2011, 13, 3290; (b) C. Zhang and N. Jiao, Angew. Chem., Int. Ed., 2010, 49, 6174 .

8 For a $\mathrm{C}-\mathrm{H}$ cyclization example with alkenes, see: $(a) \mathrm{R}$. Shi, L. Lu, H. Zhang, B. Chen, Y. Sha, C. Liu and A. Lei, Angew. Chem., Int. Ed., 2013, 52, 10582; for intra-molecular cyclization via $\mathrm{C}-\mathrm{N}$ bond cleavage, see: $(b)$ D. Yue and R. C. Larock, Org. Lett., 2004, 6, 1037; (c) B. Yao, Q. Wang and J. Zhu, Angew. Chem., Int. Ed., 2012, 51, 5170; (d) X.-F. Xia, L.-L. Zhang, X.-R. Song, Y.-N. Niu, X.-Y. Liu and Y.-M. Liang, Chem. Commun., 2013, 49, 1410; (e) B. Yao, Q. Wang and J. Zhu, Angew. Chem., Int. Ed., 2013, 52, 12992; (f) J. Sheng, S. Li and J. Wu, Chem. Commun., 2014, 50, 578; $(g)$ R. Shi, H. Niu, L. Lu and A. Lei, Chem. Commun., 2017, 53, 1908.

9 (a) X. Zhao, D. Liu, H. Guo, Y. Liu and W. Zhang, J. Am. Chem. Soc., 2011, 133, 19354; (b) Y. Kuninobu, M. Nishi and K. Takai, Chem. Commun., 2010, 46, 8860; (c) J. Shearer, C. X. Zhang, L. Q. Hatcher and K. D. Karlin, J. Am. Chem. Soc., 2003, 125, 12670; (d) S. Ueno, N. Chatani and F. Kakiuchi, J. Am. Chem. Soc., 2007, 129, 6098; (e) S. B. Blakey and D. W. C. MacMillan, J. Am. Chem. Soc., 2003, 125, 6046; (f) L.-G. Xie and Z.-X. Wang, Angew. Chem., Int. Ed., 2011, 50, 4901; C-N bond cleavage of amines: $(g)$ Y. Xie, J. Hu, Y. Wang, C. Xia and H. Huang, J. Am. Chem. Soc., 2012, 134, 20613; (h) M.-B. Li, Y. Wang and S.-K. Tian, Angew. Chem., Int. Ed., 2012, 51, 2968.

10 (a) C.-J. Li and B. M. Trost, Proc. Natl. Acad. Sci. U. S. A., 2008, 105, 13197; (b) P. T. Anastas and N. Eghbali, Chem. Soc. Rev., 2010, 39, 301; (c) M. Costas, M. P. Mehn, M. P. Jensen and L. Que Jr, Chem. Rev., 2004, 104, 939; (d) J. Piera and J. E. Backvall, Angew. Chem., Int. Ed., 2008, 47, 3506; (e) F. Cavani and J. H. Teles, ChemSusChem, 2009, 2, 508; (f) P. R. Ortiz de Montellano, Chem. Rev., 2010, 110, 932.

11 For examples of Rh-catalyzed aerobic oxidative annulations, see: (a) G. Zhang, L. Yang, Y. Wang, Y. Xie and H. Huang, J. Am. Chem. Soc., 2013, 135, 8850; (b) Y. Lu, H.-W. Wang, J. Spangler, K. Chen, P.-P. Cui, Y. Zhao, W.-Y. Sun and J.-Q. Yu, Chem. Sci., 2015, 6, 1923; (c) Q. Jiang, C. Zhu, H. Zhao and W. Su, Chem.-Asian J., 2016, 11, 356; (d) G. Zhang, H. Yu, G. Qin and H. Huang, Chem. Commun., 2014, 50, 4331; (e) C.-Z. Luo, P. Gandeepan, J. Jayakumar, K. Parthasarathy, Y.-W. Chang and C.-H. Cheng, Chem.Eur. J., 2013, 19, 14181; (f) J. Jayakumar and C.-H. Cheng, Chem.-Eur. J., 2016, 22, 1800.

$12(a) \quad$ G. Claassen, E. Brin, C. Crogan-Grundy, M. T. Vaillancourt, H. Z. Zhang, S. X. Cai, J. Drewe, B. Tseng and S. Kasibhatla, Cancer Lett., 2009, 274, 243; (b) R. M. Forbis and K. L. Rinehart, J. Am. Chem. Soc., 1973, 95, 5003; (c) A. L. Hopkins, J. Ren, J. Milton, R. J. Hazen, J. H. Chan, D. I. Stuart and D. K. Stammers, J. Med. Chem., 2004, 47, 5912; (d) A. Doleans-Jordheim, J.-B. Veron, O. Fendrich, E. Bergeron, A. Montagut-Romans, Y.-S. Wong, B. Furdui, J. Freney, C. Dumontet and A. Boumendjel, ChemMedChem, 2013, 8, 652; (e) R. W. Carling, P. D. Leeson, K. W. Moore, J. D. Smith, C. R. Moyes, I. M. Mawer, S. Thomas, T. Chan and R. Baker, J. Med. Chem., 1993, 36, 3397.

13 (a) D. V. Kadnikov and R. C. Larock, J. Org. Chem., 2004, 69, 6772; (b) T. Iwai, T. Fujihara, J. Terao and Y. Tsuji, J. Am. Chem. Soc., 2010, 132, 9602; (c) R. Zeng and G. Dong, J. Am. Chem. Soc., 2015, 137, 1408; (d) J. Wu, S. Xiang, J. Zeng, M. Leow and X.-W. Liu, Org. Lett., 2015, 17, 222; (e) R. Manikandan and M. Jeganmohan, Org. Lett., 2014, 16, 3568; $(f)$ B.-X. Tang, R.-J. Song, C.-Y. Wu, Z.-Q. Wang, 
Y. Liu, X.-C. Huang, Y.-X. Xie and J.-H. Li, Chem. Sci., 2011, 2, 2131; (g) P. J. Manley and M. T. Bilodeau, Org. Lett., 2004, 6, 2433; (h) X.-F. Yang, X.-H. Hu and T.-P. Loh, Org. Lett., 2015, 17, 1481.

14 For reviews on carbonylation reactions, see: $(a) \mathrm{X} . \mathrm{F} . \mathrm{Wu}$, H. Neumann and M. Beller, Chem. Soc. Rev., 2011, 40, 4986; (b) X.-F. Wu and H. Neumann, ChemCatChem, 2012, 4, 447; (c) X.-F. Wu, X. Fang, L. Wu, R. Jackstell, H. Neumann and M. Beller, Acc. Chem. Res., 2014, 47, 1041; (d) Q. Liu, H. Zhang and A. Lei, Angew. Chem., Int. Ed., 2011, 50, 10788.

15 For examples of carbonylation reactions, see: $(a)$ N. Chatani, T. Asaumi, T. Ikeda, S. Yorimitsu, Y. Ishii, F. Kakiuchi and S. Murai, J. Am. Chem. Soc., 2000, 122, 12882; (b) X.-F. Wu, P. Anbarasan, H. Neumann and M. Beller, Angew. Chem., Int. Ed., 2010, 49, 7316; (c) X. Fang, R. Jackstell and M. Beller, Angew. Chem., Int. Ed., 2013, 52, 14089; (d) K. Dong, X. Fang, R. Jackstell, G. Laurenczy, Y. Li and M. Beller, J. Am. Chem. Soc., 2015, 137, 6053; (e) R. Giri and J.-Q. Yu, J. Am. Chem. Soc., 2008, 130, 14082; (f) Z.-H. Guan, Z.-H. Ren, S. M. Spinella, S. Yu, Y.-M. Liang and X. Zhang, J. Am. Chem. Soc., 2009, 131, 729; (g) C. E. Houlden, M. Hutchby, C. D. Bailey, J. G. Ford, S. N. G. Tyler, M. R. Gagne, G. C. Lloyd-Jones and K. I. Booker-Milburn, Angew. Chem., Int. Ed., 2009, 48, 1830; (h) J. S. Quesnel, A. Fabrikant and B. A. Arndtsen, Chem. Sci., 2016, 7, 295; (i) Z.-H. Guan, M. Chen and Z.-H. Ren, J. Am. Chem. Soc., 2012, 134, 17490; (j) W. Li, Z. Duan, X. Zhang, H. Zhang, M. Wang, R. Jiang, H. Zeng, C. Liu and A. Lei, Angew. Chem., Int. Ed., 2015, 54, 1893; (k) W. Li, C. Liu, H. Zhang, K. Ye, G. Zhang, W. Zhang, Z. Duan, S. You and A. Lei, Angew. Chem., Int. Ed., 2014, 53, 2443; (l) J. Tjutrins and B. A. Arndtsen, Chem. Sci., 2017, 8, 1002.

16 (a) J. DeRuiter, B. E. Swearingen, V. Wandrekar and C. A. Mayfield, J. Med. Chem., 1989, 32, 1033; (b) C. Peifer, R. Urich, V. Schattel, M. Abadleh, M. Röttig, O. Kohlbacher and S. Laufer, Bioorg. Med. Chem. Lett., 2008, 18, 1431.

17 E. Sheiban and K. Wärnmark, Org. Biomol. Chem., 2012, 10, 2059.

18 T. Okuzumi, T. Yoshimura, E. Nakanishi, M. Ono and M. Murata, Novel Phenylalanine Derivatives, WO 03/ 053926 A1, July 3, 2003.

19 Computational details and references are given in the ESI. $\dagger$ 20 (a) E. A. Lewis and W. B. Tolman, Chem. Rev., 2004, 104, 1047; (b) L. M. Mirica, X. Ottenwaelder and T. D. P. Stack, Chem. Rev., 2004, 104, 1013; (c) S. T. Prigge, B. A. Eipper, R. E. Mains and L. M. Amzel, Science, 2004, 304, 864; (d) W. Nam, Acc. Chem. Res., 2007, 40, 465; (e) J.-S. Tian and T.-P. Loh, Angew. Chem., Int. Ed., 2010, 49, 8417; (f) S. Guo, B. Qian, Y. Xie, C. Xia and H. Huang, Org. Lett., 2011, 13, 522; (g) S. Mahapatra, J. A. Halfen and W. B. Tolman, J. Am. Chem. Soc., 1996, 118, 11575. 